\title{
Las presuposiciones filosóficas de la investigación teológica (bíblica y sistemática)
}

\author{
Joel Turpo ${ }^{1}$ \\ ${ }^{1}$ Universidad Peruana Unión
}

Recibido: 04 de diciembre de 2016

Aceptado: 01 de enero 2017

\begin{abstract}
Resumen
La presente investigación revisa el proceso que llevó a la teología a ser influenciada por las categorías de la filosofía griega. Tal proceso se estudia en la metodología histórica-crítica propia de la teología bíblica y en la concepción de la realidad del sistema teológico. En este sentido, se plantea que tanto la concepción del ser de Dios, la realidad, las doctrinas y la naturaleza del hombre han incurrido en varios errores bíblico-teológicos por causa de la influencia del marco filosófico griego que ha calado fuertemente en la metodología para hacer teología bíblica, es decir en la exégesis y en las presuposiciones para la elaboración de una teología sistemática.
\end{abstract}

Palabras clave: Presuposición, teología sistemática, teología bíblica, filosofía, hermenéutica.

\begin{abstract}
This research examines Greek philosophical categories influence on theology. This will do through the historical-critical method of biblical theology and in the reality conception of the theological system. In this sense, it is argued that both conception of God's being, reality, doctrines and the nature of man have incurred several biblical-theological errors because of Greek philosophical framework influence that has penetrated strongly in the method to do biblical theology, that is to say in exegesis and in the presuppositions for elaboration of a systematic theology.
\end{abstract}

Keywords: Presuppositions, Systematic Theology, Biblical Theology, Philosophy, Hermeneutics.

\footnotetext{
${ }^{1}$ Correspondencia al autor

E-mail: joelt@upeu.edu.pe
} 


\section{Introducción}

Siendo que el acto de la interpretación misma se realiza desde dentro de un marco cultural y teológico (Osborne, 2006, p. 467) que está fundamentado por una filosofía particular que se compone de premisas, suposiciones y presuposiciones. La lectura del texto bíblico no escapa a esta situación. Así cuando se consulta la Biblia se la lee bajo la cuadrícula de una filosofía específica que permea la cultura y las nociones teológicas. Tal filosofía se compone de un esquema conceptual que funciona como una sistema dentro de una cosmovisión, la que permite interpretar la realidad como un todo (Nash, 1988)

Dentro de la hermenéutica bíblica, el estudio de las presuposiciones se encuentra en el campo del lector y su posición al ser confrontado con el texto. Canale (1998, p. 26) argumenta:

Una presuposición es cualquier cosa que el sujeto cognitivo trae dentro de la actividad de conocimiento. Aún los prejuicios juegan un rol presuposicional. Un sistema trabaja dentro del conocimiento en el nivel de las presuposiciones. Todavía el sistema es una clase especial de presuposición última, definitiva. Es última, debido a que no puede ser verificada o cambiada sin cambiar al mismo tiempo la ciencia que esta fundamenta.

Al mismo tiempo, una cosmovisión está enraizada en conceptos pre-teoréticos y presuposiciones que son el fundamento para todo el pensamiento y acción (Sims, 2006, p.11). Por lo cual, la cosmovisión se sostiene por presuposiciones últimas, finales (Sims, 2006, p. 43). De este modo, el conocimiento trabaja con presuposiciones que en su misma esencia están formados por la cultura y la filosofía que la persona adopta.

Marías (1975, p. 181, 182, 205-216, 263) reconoce este hecho, al comentar que Esto se debe a que los sistemas filosóficos tienen consecuencias históricas, de tal forma que el pensamiento de la época es condicionado por la filosofía. En este sentido, las ideas filosóficas se van generalizando hasta convertirse en partes del influjo social.

Varios teólogos reconocen este hecho. Leggett (1977, p. 1), por ejemplo, lo advierte del siguiente modo: "se puede decir que la teología sistemática tiene raíces más fundamentales en la filosofía neoplatónica del mundo helénico que en la iglesia primitiva. Por su parte Roldán (2011, p. 41) menciona que "tradicionalmente, la filosofía griega ha sido el instrumental con el que se manejó la teología sistemática, platónica o aristotélica. A su vez Cullmann (1968, p. 42) refiere: “A través de toda la historia de los dogmas y hasta en nuestros días, se ha producido así un grave 
equívoco que hace admitir como ‘cristiano’ lo que en realidad es griego”. Finalmente Canale menciona: "las categorías fundamentales de la filosofía griega fueron tomadas como contexto sistemático ideológico fundamental reemplazando así el histórico-teológico del AT. El sistema de inteligibilidad se desplaza de la Biblia a la naturaleza y atemporalidad de la filosofía griega ${ }^{30}$

En este sentido, el estudio plantea que la metafísica griega-occidental forma el carácter presuposicional de la mayoría de las metodologías teológicas, sean bíblicas o sistemáticas. La presente investigación analiza esta influencia en el método histórico crítico dentro de la disciplina de la teología bíblica y en el marco de la interpretación de la realidad con la cual se construye la teología sistemática

\section{El marco conceptual de la teología bíblica}

Las raíces de la teología bíblica están intrínsecamente unidas al surgimiento del criticismo histórico (Hasel, 1991) ${ }^{31}$ que todavía constituye, para muchos eruditos, en la norma de interpretación bíblica (Bray, 1996; Kerbs, 2002). Mead (2007) comenta que “los grandes teólogos de la edad de oro - como Eichrodt, von Rad, y Bultmann - todos entendieron su trabajo como principiando con y siendo fundamentado en las ideas de la investigación histórica-crítica”.

De acuerdo con Troeltsch (1922) ${ }^{32}$ sus fundamentos están basados en (1) el principio de analogía, que aplica significados de lo conocido en el presente a lo desconocido en el pasado, es decir aplica la homogeneidad de todos los eventos históricos, en ese sentido el conocimiento del presente es la clave para interpretar el pasado. Lo que significa que para algunos teólogos la realidad presente determina la comprensión de la realidad del Antiguo Testamento (AT) o Nuevo Testamento (NT); (2) el principio de correlación, que mira la historia como una unidad cerrada de causa y efecto en la cual no hay lugar para la intervención sobrenatural, e interpreta los eventos bíblicos sobrenaturales como originados por causas históricas inmanentes, es decir por causas humanas o simplemente naturales pero no divinas, y por tanto considera a la Biblia como una simple producción literaria; (3) el principio crítico, que subordina la Escritura a la razón humana y

\footnotetext{
${ }^{30}$ Fernando Canale, “Secularización e Historia de la cristiandad”. Enfoques 5, n 1 (1993), 13.

${ }^{31}$ Para una revisión de las variadas facetas del método histórico crítico véase Haynes and McKenzie (1999); Soulen (1981); Knierim (1985); Hayes and Holladay (2007); Bray (1996).

32 Para mayor información de la crítica a los principios de Troeltsch véase Hasel (1985), 73-77; Kerbs (2003); Nations (1983); Pereyra (2000
} 
se basa en la duda sistemática que los historiadores aplican a todas las tradiciones históricas (Pereyra, 2000).

En esencia, en base a estos tres principios, el método histórico-crítico niega la inspiración de la Escritura (Farnell, 1998), de tal modo que la teología bíblica sólo podría ofrecer grados y probabilidades, pero nunca hechos asegurados (Hasel, F., 1996).

\section{La influencia de la filosofía en la teología bíblica}

Las raíces del método histórico-crítico vienen de las presuposiciones y premisas filosóficas (Geisler, 2004).

Garrett (1996, p. 33) menciona:

Los teólogos cristianos a menudo han sido influenciados significativamente por corrientes intelectuales dentro de sus culturas. Muchas veces sin saberlo. Ejm: padres de la iglesia por el neoplatonismo, Tomás de Aquino por Aristóteles, los teólogos del siglo XVIII por la ilustración, los teólogos del siglo XIX por Charles Darwin; los teólogos de la liberación a fines del siglo XX por el marxismo-leninismo. La interacción con tales movimientos intelectuales incluyó el apropiarse de conceptos, descubrimientos y/o términos provenientes de estas corrientes.

Revisando la forma de pensamiento que marcó la época, nos remitimos a Descartes (15961650), quien inaugura la filosofía moderna. De acuerdo a García Morente (1943), Descartes traslada la discusión filosófica comenzada en Grecia, a nuevos planteamientos en que la duda viene a ser el método esencial de su filosofía. De este modo, funda su especulación en el criterio de evidencia de la razón. Por tanto, el método cartesiano es el racionalismo. Asimismo el sistema de Descartes es también idealista. Marías (1975) explica muy bien en qué consiste este idealismo en contraposición del realismo:

El idealismo es la tesis opuesta al realismo metafísico. El realismo - Grecia y la edad media - cree que las cosas tienen un ser por sí, que yo existo simplemente entre ellas y la verdadera realidad son las cosas - res -. Ser quiere decir ser en sí, ser independiente de mí. El idealismo, por el contrario piensa que no sé nada seguro más que yo mismo (el cogito); que solo sé de las cosas en cuanto las veo, las toco, las pienso, las quiero, etc. (la palabra cogitatio no significa solo pensar, sino todo acto psíquico); es decir, en cuanto están en relación conmigo y soy testigo de ellas. No sé ni puedo saber cómo son las cosas aparte de mí; ni siquiera si existen en mí, pues nada sé de ellas sin estar presente. Es decir, las cosas aparecen como siendo para mí; son, pues, por lo pronto, ideas mías y la realidad que les corresponde es esa ideal. El yo funda el ser de las cosas, como ideas suyas; esto es el 
idealismo $^{33}$

A partir del método (racionalista) y sistema (idealista) de Descartes se establece el predominio absoluto del intelecto, del entendimiento y de la razón, los cuales intensamente influirán en el pensamiento del mundo, de la ciencia, y de la vida (García Morente, 1943). Marías (1975) afirma que el racionalismo cartesiano es también la causa del espíritu igualmente apriorista y anti-histórico que informa todo el siglo siguiente y culmina en forma dramática en la revolución francesa.

Esta filosofía racional, aunque anclada en Descartes, llega a sus máximos desarrollos con Kant (1724-1804), para quien, en palabras de González (1993, p. 348): “la mente puede conocer los fenómenos solamente cuando los coloca en sus propias estructuras fundamentales, el tiempo y el espacio... Si hay fenómenos que no se ajustan a esos patrones, la mente no puede conocerlos, puesto que se encuentran allende al alcance de la cognición y experiencia humanas”.

Por lo que para Kant, la única función de la religión es apoyar la vida moral. En este sentido el idealismo alemán, en Kant, acaba de perder totalmente a Dios en la razón especulativa, al declarar imposible la prueba ontológica, ya que Dios, por su índole misma de ente infinito no es susceptible a la intuición, resulta, por tanto, separado de toda experiencia posible (Marías, 1975).

Asimismo, tal influencia se plasma en el empirismo (siglos XVI-XVIII), la ilustración (siglo XVIII) y el idealismo alemán (siglos XVIII y XIX), que a su vez fueron el influjo que necesitaban el escepticismo, el deísmo o religión natural, el racionalismo, el humanismo, el inductivismo, el naturalismo, el materialismo, el ateísmo, el sensualismo, el anticristianismo, el secularismo, el agnosticismo, el romanticismo, el evolucionismo y el existencialismo, los cuales llegan hasta nuestra época y que, en su base conceptual, son contrarios a la visión ortodoxa de la Biblia (Bray, 1996; Farnell, 1998; Frei, 1974; Geisler, 2004, 2004, 2004; Harrisville \& Sundberg, 2002; Kerbs, 2002, 2003; Linnemann, 1990; Marías, 1975).

De este modo, la filosofía moderna estableció el punto de partida ateo para el estudio de las ciencias y que constituyeron el fundamento de la crítica bíblica (Linnemann, 1990). En este sentido

\footnotetext{
${ }^{33}$ Las cursivas están en el original. Otra explicación del idealismo en contraste con el realismo se encuentra en García Morente (1943, p. 143-148).
} 
Geisler (2004, p. 8) menciona que:

The philosophical "air" is alive with everything from Bacon's inductivism to Heidegger's mysticism: with Hume's skepticism, Kant's agnosticism, Hegel's transcendentalism, Kierkegaard's existentialism, Nietzsche's atheistic relativism, and Wittgenstein's linguistic noncognitivism. Few errantists may admit the influences of most of these men on their thinking, but only the naïve and untrained can miss the marks of these philosophers in their writings.

Como resultado, desde su origen la disciplina de la Teología Bíblica ha sido separada de su aspecto teológico (Hasel, 1994) Klink \& Lockett (2012, p. 15) al comentar sobre Gabler (17531826), el padre de la teología bíblica, mencionan:

He argued that biblical theology was merely an independent historical project, which could proceed without reference to larger synthetic questions (especially those of the dogmatic teachings of the church). The effects is that roughly from the time of Gabler up until the twentieth century, biblical theology and systematic theology were viewed in sharp contrast with one another.

Por lo cual, la teología bíblica ha sido forzada a jugar el rol de una disciplina histórica y descriptiva (Hasel, 1996) que no tiene mayor importancia para prescribir la fe y el estilo de la vida cristiana. A continuación se revisa el impacto de la filosofía en la teología sistemática.

\section{Marco conceptual de la teología sistemática}

Por definición, un sistema teológico es un todo de piezas articuladas o más específicamente, un todo cognitivo de doctrinas teológicas articuladas. Watson (2012, p. 85) considera que esta sentencia puede ser expresada en la fórmula: “ $x$ ” = “y” donde “ $x$ ” es cualquier sistema $y$ “ $y$ ” es un “todo de partes articuladas”. Asimismo, Watson (2012, p. 243) en su conclusión redefine el significado de sistema como "any structure of theological doctrines or principles articulated in a way that results in the fulfillment of the whole anticipated by its transcendental principle”. Hasel (1995), por su parte, define la teología sistemática como la construcción de un sistema teológico de creencias en relación con Dios y el hombre, el pecado y la salvación, la visión del mundo desde la perspectiva de la divinidad, la iglesia presente y el futuro reino a venir.

La tarea de la sistemática consiste en reunir los hechos, establecidos en las doctrinas, y esforzarse por integrarlos en un todo asimilable (Lonergan, 1988). De esta manera, la teología sistemática intenta sistematizar las creencias de la fe cristiana y trata de expresar de manera sintética los hilos de un sistema completo (Fackre, 1995). 
En esta tarea, cada sistema se erige en base a una cosmovisión, que funciona como presuposiciones implícitas (Turpo, 2012). La cosmovisión traza los límites del sistema y tiene el potencial de influenciarlo (Gulley, 2003). Si la cosmovisión está errada, el sistema expondrá defectos. Por lo que se asume que la teología sistemática fue impactada por filosofías extra Scriptura que modificaron su cosmovisión y la llevaron a un proceso de secularización.

\section{La influencia de la filosofía en la teología sistemática}

Lo que está en el trasfondo del método histórico-crítico y que ha calado fuertemente en la metodología de la teología sistemática es la interpretación de la realidad que asienta sus fundamentos, más allá de Descartes, en la filosofía griega (Kerbs, 2003). La interpretación de la realidad fue introducida por Parménides (García Morente, 1943) ${ }^{34}$ quien, basado en su principio de identidad (principio lógico del pensamiento: el ser es, el no ser no es) evidencia que el ser es único, eterno, inmutable, ilimitado e inmóvil en contraste con el mundo de las cosas que es completamente distinto de este mundo atemporal. Las cosas son pluralidad, temporalidad, mutabilidad, limitación y movimiento, es una oposición del ser. Esta percepción cambió la concepción de la cosmovisión del mundo. Así, este mundo sensible es una apariencia, una ilusión de nuestros sentidos, una ilusión de nuestra facultad de percibir que resultan incomprensibles ante la razón. Para Parménides la guía para descubrir la verdad del ser está en la razón. Así la razón del hombre es la regla, el fundamento para resolver los problemas del ser, que descubre la realidad. De este modo, hay un mundo sensible (temporal) y un mundo inteligible (atemporal), ambos totalmente contrapuestos. Con esto, se establecen los pilares fundamentales de la metafísica griega (García Morente, 1943).

Esta visión dual del mundo es seguida por Platón, quien concibe al mundo de las ideas como atemporal y el mundo sensible, material. Platón ha considerado las ideas como entes reales, que existen en sí y por si, que pertenece al mundo inteligible, distinto, separado y contrapuesto al mundo sensible que es el mundo del no ser, de la apariencia, del “phainómenos” (fenómeno). Las ideas son pues, para Platón “trascendentes” a las cosas (García Morente, 1943; Guillermo Fraile, 1971; Leggett, 1977).

\footnotetext{
${ }^{34}$ García Morente (1943, p. 67) reconoce que seguimos viviendo hoy en los mismos carriles y cauces filosóficos que fueron abiertos por Parménides de Elea.
} 
Aristóteles continúa con esta percepción de la realidad en su concepción de la "materia” que es mutable, temporal, material, que no determina el ser de la cosa en contraposición de la “forma” que es inmutable, atemporal, inmaterial, que determina el ser de la cosa (Kerbs, 2014). De este modo, aunque la tarea de Aristóteles se centra en introducir las ideas platónicas dentro de la misma realidad sensible (García Morente, 1943; Guillermo Fraile, 1971), en su concepción de “materia” y "forma reaparece la concepción de los dos mundos (el cambiante y el inmutable) de Platón” (Kerbs, 2014).

El neoplatonismo también sostuvo la postura esencial de Platón acerca de que la realidad no-sensible (las formas ideales) es superior a la física. Para el fundador del neoplatonismo, Plotino, toda realidad consiste en una serie de emanaciones del Uno, fuente eterna de todo ser. Este Uno es la base de toda la existencia pero en sí misma es inmaterial, trascendente e impersonal. La primera emanación del uno se llama el Nous, que significa espíritu o inteligencia. La segunda emanación es Psyché, el alma, esta significa vida, el principio del movimiento en el pensamiento griego. Las almas descienden al mundo físico donde habitan en cuerpos y tienen existencia corporal. Todo lo material en el cosmos tiene alma. Pero solamente en el ser humano el alma tiene conciencia completa. El principio racional y gobernador del universo es el logos, que es el lado dinámico del Nous y da orden y estructura al cosmos (Guillermo Fraile, 1971; Tillich, 1976).

Gracias a la influencia del neoplatonismo, la noción de la realidad dual (temporalatemporal) de los conceptos filosóficos griegos, ingreso al torrente sanguíneo del cristianismo, esencialmente con respecto a las doctrinas de Dios, el mundo y el alma (Tillich, 1976), por medio de los padres de la iglesia y de manera especial por Agustín de Hipona (354-430), cuyo pensamiento dominó la primera parte de la Edad Media (González, 2002; Marías, 1975).

Asimismo, En la Escolástica, la inmensa labor de Tomás de Aquino consiguió incorporar al pensamiento cristiano la filosofía aristotélica (Marías, 1975). El mismo Marías (1975) reconoce que fue un problema gravísimo el incorporamiento de la mente aristotélica a la filosofía cristiana, de tal forma que se malograron posibilidades originales que hubieran alcanzado en su madurez siguiendo otro camino.

Esta visión de la realidad de Dios, el mundo y el alma como atemporal y temporal, material y espiritual, ha estado presente en la Reforma y el Protestantismo hasta nuestros días. Así, en la 
Reforma, Lutero y Calvino utilizaron los elementos básicos griegos que heredaron de Agustín y su neoplatonismo (Canale, 2012). Lutero lo utilizó para la construcción de la doctrina de la justificación por la fe; y Calvino para la elaboración de sus conceptos de predestinación, pecado y gracia (Leggett, 1977; Tillich, 1976).

La ortodoxia protestante continuó trabajando sobre los carriles de la filosofía griega (Leggett, 1977). Kerbs (2014, p. 612) menciona: “La filosofía entró en la ortodoxia protestante por la puerta que los grandes reformadores habían dejado abierta a la teología tradicional”. Un ejemplo de esto es el discípulo de Lutero, Melanchthon, quien buscó en el sistema aristotélico el fundamento para la teología luterana. Los teólogos posteriores continuaron usando las categorías aristotélicas. Lo mismo ocurrió en la teología calvinista, lo que dio un carácter muy racional a la teología (Tillich, 1976).

Hasel, F. (1996, p. 118) comenta que la sistemática tradicional es dependiente de tradiciones, contenido y métodos filosóficos, y usa la Escritura solamente para comprobar una agenda teológica particular que está derivada independientemente de ella. Por lo tanto, las categorías fundamentales de la filosofía griega fueron tomadas como contexto sistemático ideológico fundamental para la construcción de la realidad, la interpretación de la Biblia, la exposición de las doctrinas y el ser de Dios que reemplazo la concepción histórica-teológica del AT (Canale, 1993; Kerbs, 2014) $)^{35}$

\section{Conclusiones}

El problema, de acuerdo con Cullmann (1968, p. 43) es que la concepción cristiana primitiva de la historia de la salvación ligada a la línea temporal ascendente se disolvió en la metafísica de la noción griega. Para Kerbs, (2014, p. 27) el problema radica en que “el pensamiento teológico cristiano, tanto católico romano como protestante, no ha fundado la hermenéutica bíblica y la teología sobre la interpretación bíblica de las presuposiciones básicas de la mente, sino sobre la interpretación filosófica griega de las mismas”.

De este modo, la visión de la realidad (atemporal y temporal), junto con el predominio de

\footnotetext{
${ }^{35}$ Watson (2012, p. 231-233) menciona que inclusive la innovación del uso de la palabra “sistema” por Keckermann fue un matrimonio de tipo del método de Ramist y el contenido aristotélico. Para mayor información véase Canale (1987).
} 
una filosofía mucho más racional, han dado forma y han separado a la teología bíblica y sistemática (Hasel, 1984; Hasel, F., 1996; Perdomo, 2004). Logrando que sean regidas por la razón (Tillich, 1976) y que, en ellas, el ser de Dios, la realidad junto con las doctrinas y la concepción del alma se pierdan en la trascendencia atemporal, eliminando así, todo aquello que en la interpretación no concuerda con la realidad atemporal que la razón asume. Porque Dios, al ser atemporal, no puede revelarse en la historia, pues lo finito no puede alcanzar lo infinito (finitum non capax infiniti) (Canale, 1993). Por consiguiente, la Biblia no es más la revelación cognitiva de Dios, y entonces se busca explicar su origen a partir de causas naturales, identificadas por medio del estudio del proceso literario de composición y compilación de fuentes, buscando la verdad atemporal dentro del ámbito del significado temporal (Harrison, 1990; Hasel, 1984).

De allí, se asume que la teología bíblica es una disciplina puramente descriptiva concerniente al descubrimiento de lo que los escritores bíblicos pensaron y enseñaron (ámbito temporal) que se distingue de la teología bíblica pura, que es la presentación sistemática de la verdad eterna de Dios (ámbito atemporal) (Gabler, 1992), a partir de este enfoque surge la distinción entre el Cristo de la fe (atemporal) y el Cristo histórico (temporal); o el Cristo kerigmático (atemporal) y el Jesús histórico (temporal); o la Geschichte (atemporal) y la Historie (temporal) (Bray, 1996; Kerbs, 2002, 2003, 2004).

El desafío consiste en fundamentar una filosofía que se enmarque en el sistema de pensamiento bíblico-teológico que reformule las presuposiciones filosóficas del ser de Dios, la realidad, las doctrinas y la concepción del hombre. Tal empresa debe ser elaborada desde la perspectiva de la teología bíblica y sistemática, de tal forma que replantee, transforme y rebautice el método por uno que reconozca la lógica y coherencia del sistema de pensamiento bíblico. 


\section{Referencias}

Bray, G. L. (1996). Biblical Interpretation: Past \& Present. Downers Grove, IL: IVP Academic. Retrieved from http\%3A//www.worldcat.org/oclc/729835042

Canale, F. (1993). Secularización e Historia de la cristiandad. Enfoques, 5(1), 11-18.

Canale, F. L. (1987). A Criticism of Theological Reason: Time and Timelessness as Primordial Presuppositions. Andrews University Seminary doctoral dissertation series: v. 10. Berrien Springs, MI: Andrews University Press.

Canale, F. L. (1998). Paradigm, System, and Theological Pluralism. The Evangelical Quarterly, 70, 195-218.

Canale, F. L. (2012). ¿Adventismo secular?: Cómo entender la relación entre estilo de vida y salvación. Ñaña, Lima, Peru: Publicaciones y Difusión Cultural, Universidad Peruana Unión.

Cullmann, O. (1968). Cristo y el tiempo. Teología sistemática. Barcelona: Estela.

Fackre, G. (1995). The Revival of Systematic Theology. Interpretation, 44(3), 229-241.

Farnell, F. D. (1998). Philosophical and Theological Bent of Historical Criticism. In R. L. Thomas \& F. D. Farnell (Eds.), The Jesus Crisis. The Inroads of Historical Criticism into Evangelical Scholarship (pp. 85-131). Grand Rapids, MI: Kregel Publications.

Frei, H. W. (1974). The Eclipse of Biblical Narrative: A Study in Eighteenth and Nineteenth Century Hermeneutics. New Haven: Yale University Press.

Gabler, J. P. (1992). An Oration on the Proper Distinction between Biblical and Dogmatic Theology and the Specific Objectives of Each. In B. C. Ollenburger, E. A. Martens, \& G. F. Hasel (Eds.), The Flowering of Old Testament Theology. A Reader in Twentieth-Century Old Testament Theology, 1930-1990 (Vol. 1). Winona Lake Ind.: Eisenbrauns.

García Morente, M. (1943). Lecciones preliminares de filosofía (3. ed). Biblioteca filosófica: no. 164. Buenos Aires: Editorial Losada.

Garrett, J. L. (1996). Teología sistemática: Biblica, historica y evangelica. El Paso, TX: Casa Bautista de Publicaciones.

Geisler, N. (2004). Biblical Errancy: An Analysis of its Philosophical Roots: Wipf \& Stock Publishers.

González, J. L. (1993). Historia del pensamiento cristiano. Miami, Florida: Editorial Caribe. González, J. L. (2002). Historia del pensamiento cristiano (ed. rev., vol. 1). Nashville, TN: Caribe.

Guillermo Fraile. (1971). Historia de la filosofía (vol. 1, Grecia y Roma). Madrid: Ariel.

Gulley, N. R. (2003). Systematic theology: Prolegomena (vol. 1). Berrien Springs, MI:Andrews University Press.

Harrison, R. K. (1990). Introducción al Antiguo Testamento (vol. 1). Jenison, MI: T.E.L.L. Harrisville, R. A., \& Sundberg, W. (2002). The Bible in Modern Culture: Baruch Spinoza to Brevard Childs (2nd ed.). Grand Rapids, MI: W.B. Eerdmans Pub. 
Hasel, F. (1995). Scripture in the Theologies of W. Pannenberg and D. G. Bloesch. An Investigation and Assessment of its Origin, Nature, and Use (Disertación Doctoral en Teología). Andrews University, Michigan, Estados Unidos.

Hasel, F. (1996). Algunas reflexiones sobre la relación entre la Teología Sistemática y la Teología Bíblica. Theologika, 11(1), 102-123.

Hasel, G. (1996). Proposals for a Canonical Biblical Theology. Andrews University Seminary Studies, 34(1), 23-33.

Hasel, G. F. (1984). The Relationship between Biblical Theology and Systematic Theology. Trinity Journal, 5(2), 113-127.

Hasel, G. F. (1985). Biblical Interpretation Today: An Analysis of Modern Methods of Biblical Interpretation and Proposals for the Interpretation of the Bible as the Word of God. Lincoln, Nebraska: College View Printers-Biblical research Institute.

Hasel, G. F. (1991). Old Testament Theology: Basic Issues in the Current Debate (4th ed., rev., updated \& enl). Grand Rapids, MI: W.B. Eerdmans.

Hasel, G. F. (1994). The Nature of Biblical Theology. Andrews University Seminary Studies, 32(3), 203-215.

Hayes, J. H., \& Holladay, C. R. (2007). Biblical Exegesis: A Beginner's Handbook (3rd ed). Louisville, Ky.: Westminster John Knox Press.

Haynes, S. R., \& McKenzie, S. L. (Eds.). (1999). To Each its Own Meaning: An Introduction to Biblical Criticisms and their Applications (Rev. and expanded). Louisville, Ky.: Westminster John Knox Press.

Kerbs, R. (2002). El método histórico-crítico en teologiá: en busca de su estructura básica y de las interpretaciones filosóficas subyacentes (parte I). DavarLogos, 1(2), 105-123.

Kerbs, R. (2003). El método historico-crítico en teología: en busca de su estructura básica y de las interpretaciones filosóficas subyacentes (parte II). DavarLogos, 2(1), 1-27.

Kerbs, R. (2004). La crítica del Pentateuco y sus presuposiciones filosóficas. In G. A. Klingbeil (Ed.), Inicios, paradigmas y fundamentos. Estudios teológicos y exegéticos en el Pentateuco (pp. 3-43). Entre Ríos, Argentina: Editorial Universidad Adventista del Plata.

Kerbs, R. (2014). El problema de la identidad bíblica del cristianismo: Las presuposiciones filosóficas de la teología cristiana: desde los presocráticos al protestantismo. Lib. San Martín, Entre Ríos: Editorial Universidad Adventista del Plata.

Klink, E. W., \& Lockett, D. R. (2012). Understanding biblical theology: A comparison of theory and practice. Grand Rapids, Mich.: Zondervan.

Knierim, R. (1985). Criticism of Literary Features, Form, Tradition, and Redaction. In D. A. Knight \& G. M. Tucker (Eds.), Centennial publications / Society of Biblical Literature: Vol. 1. The Hebrew Bible and its Modern Interpreters (pp. 123-153). Chico, Calif.: Scholars Press. 
Leggett, P. (1977). ¿Platón o Jesucristo? Presupuestos filosóficos en la teología sistemática con referencia al tema de la liberación humana. San José, Costa Rica: Seminario Bíblico Latinoamericano.

Linnemann, E. (1990). Historical Criticism of the Bible: Methodology or Ideology? Grand Rapids, Mich.: Baker Book House.

Lonergan, B. J. F. (1988). Método en teología. Salamanca: Ediciones Sígueme.

Marías, J. (1975). Historia de la filosofía (28. ed. nuevamente ampliada). Biblioteca de la Revista de Occidente: 8 : Sección de filosofía. Madrid: Ediciones de la Revista de Occidente.

Mead, J. K. (2007). Biblical Theology: Issues, Methods, and Themes. Louisville, Ky.: Westminster John Knox Press.

Nash, R. H. (1988). Faith \& Reason: Searching for a Rational Faith. Grand Rapids, Mich.: Academie Books.

Nations, A. L. (1983). Historical Criticism and the Current Methodological Crisis. Scottish Journal of Theology, 36(1), 59-71.

Osborne, G. R. (2006). The Hermeneutical Spiral: A Comprehensive Introduction to Biblical Interpretation (Rev. and expanded, 2nd ed.). Downers Grove, Ill.: InterVarsity.

Perdomo, E. A. (2004). Algunas tensiones metodológicas en la teología evangélica latinoamericana de principios del siglo XXI. (Segundo de dos partes). Kairós, 35, 55-80.

Pereyra, R. (2000). El método histórico crítico: un debate adventista contemporáneo. In K. M. Alomia, G. Klingbeil, M. Klingbeil, \& J. Torreblanca (Eds.), Entender la palabra. Interpretación adventista para el nuevo siglo: segundo Simposio Bíblico-teológico Sudamericano, Universidad Adventista de Bolivia, 29-31 de octubre de 1999 (1st ed., pp. 5976). Cochabamba, Bolivia: Editorial UAB.

Roldán, A. F. (2011). ¿Para qué sirve la teología? Grand Rapids, Michigan: Libros Desafío. Sims, B. B. (2006). Evangelical Worldview Analysis. A Critical Assessment and Proposal (Ph. D. Diserttation). Southern Baptist Theological Seminary, Louisville, Kentucky. Retrieved from http://digital.library.sbts.edu/handle/10392/407

Soulen, R. N. (1981). Handbook of Biblical criticism (2nd ed.). Atlanta, Ga.: J. Knox Press.

Tillich, P. (1976). Pensamiento cristiano y cultura en Occidente: primera parte: de los orígenes a la reforma. Buenos Aires: La aurora.

Troeltsch, E. (1922). Zur religiösen Lage, Religionsphilosophie und Ethik. Tübingen: Mohr. Turpo, J. (2012). Ética, liderazgo y cosmovisión bíblica frente a la cosmovisión naturalista. Apuntes Universitarios, 2(2), 91-100.

Watson, T. (2012). The Meaning and Function of System in Theology (Disertación doctoral en Teología). Andrews University, Michigan, Estados Unidos. Retrieved from http://search.proquest.com/docview/944324825\#top 